\title{
Оценка адаптивности перспективных образцов фасоли овощной в условиях Лесостепи Приобья
}

Якубенко О.Е.*, преподаватель, Паркина О.В., к.с.-х.н., доцент; Плотников К.О., студент.

ФГБОУ ВО Новосибирский ГАУ, г. Новосибирск, Россия

*e-mail: o.e.yakubenko@yandex.ru

Оиенка адаптивного потенциала сортов является актуальным направлением в области селекции. Главным условием для создания высококачественного сорта является сочетание в нем экологической пластичности и продуктивности. При этом большое внимание уделяется параметрам, оказывающим влияние на потенцииальную урожайность сорта. На кафедре селекиии, генетики и лесоводства ФГБОУ ВО Новосибирский ГАУ проведена многолетняя оценка (2017-2019 г2.) перспективных линий фасоли овошной.Выделены генотипы культуры, которые сочетают высокую продуктивность со средовой устойчивостью.

Ключевые слова: фасоль обыкновенная, адаптивность, коэффичиент регрессии, селекционная цеенность генотипа, экологическая пластичность, лесостепь Приобья.

\section{The appraisement of adaptive ability of perspective lines of common bean in the conditions of the Western Siberia}

Yakubenko O.E., Parkina O.V., Plotnikov K.O.

Novosibirsk State Agrarian University, Novosibirsk, Russia.

*e-mail: o.e.yakubenko@yandex.ru

The evaluation of adaptive ability of varieties is an actual direction in selection. The main condition for creating a high-quality variety is a combina-tion of ecological plasticity and productivity. At the same time, much attention is paid to the parameters that affect the potential yield of the variety. On the basis Department of Selection, Genetics and Forestry, Novosibirsk State Agrar-ian University (2017-2019), long-term evaluation of perspective lines of green bean. As a result of the study genotypes of the crop, combining high productivi-ty and environmental resistance, were selected.

Key words: common bean, adaptability, regression coefficient, the breeding value of the genotype, environmental plasticity, Western Siberia. 
Фасоль обыкновенная овощного направления обладает высокими вкусовыми и диетическими свойствами, широко используется в кулинарии. Для России фасоль, выращиваемая на зеленую лопатку, является относительно новой культурой. Незначительное распространение связано с недостаточным набором экологически пластичных сортов. Для создания адаптивных, высокопродуктивных образцов необходимо при подборе родительских пар отдавать предпочтение генотипам с высокой селекционной ценностью.

Методы целенаправленного выведения высокоадаптивных сортов и сортов интенсивного типа к настоящему времени недостаточно разработаны. Обычно учитывают норму реакции генотипа, которая является наследственной. Высокоадаптивные сорта могут быть использованы в производственных условиях повсеместно, а сорта интенсивного типа лучшие результаты смогут показать в хозяйствах с высоким уровнем культуры земледелия.

В настоящее время в ассортименте овощных культур более распространены сорта высоко- и среднеадаптивные. Их ценность заключается в том, что эти образцы более устойчивые к экологическим изменениям среды, но не отличаются высокой урожайностью. Для отбора интересующих селекционера форм, прибегают к изучению такого показателя, как селекционная ценность генотипа. В этом случае равное значение придается продуктивности и стабильности.

На базе УПХ «Сад Мичуринцев» Новосибирского ГАУ был проведен опыт по изучению адаптивного потенциала селекционных линий фасоли овощного направления в 2017-2019 годах [4].

Цель исследования - оценить адаптивность перспективных линий фасоли овощной в условиях лесостепи Приобья.

Фенологические и морфологические наблюдения проводили в соответствие с принятыми методиками ВИР [2, 3]. Один из эффективных методов по оценке адаптивности генотипов разработан А.В. Кильчевским и Л.В. Хотылевой (1985). Согласно этому методу реакцию сорта характеризуют общая адаптивная способность (ОАС) - среднее значение признака в различных условиях выращивания и специфическая адаптивная способность (САС) - отклонение от ОАС в определенной среде. Введен комплексный показатель селекционной ценности генотипа (СЦГ), позволяющий выделить генотипы, сочетающие высокую продуктивность со средовой устойчивостью [1].

Уровень урожайности служит главным критерием экономической целесообразности возделывания сорта. Создание сорта с высоким генетическим потенциалом продуктивности не гарантирует получение высоких урожаев при его возделывании.

По признаку урожайность зеленых бобов в 2017-2019 года изучено 9 генотипов перспективных форм фасоли овощного направления. Стандартом выступает сорт сибирской селекции Солнышко, отличающийся высокими показателями продуктивности и адаптивности. 
Коэффициент регрессии позволяет определить к какому типу относится изучаемый образец. При значении параметра больше единицы форма относится к интенсивному типу, которая характеризуется высокой отзывчивостью и пластичностью. Значение коэффициента меньше нуля или приближенное к нулю позволяет сделать вывод о низкой адаптивности сорта к изменениям окружающей среды и отнести его к нейтральному типу. Изучаемые линии по признаку урожайность имеют коэффициент регрессии отрицательный или приближенный к нулю, что позволяет нам отнести формы к нейтральному типу (таблица).

Таблица - Оценка адаптивности линий фасоли овощной по признаку урожайность зеленых бобов

\begin{tabular}{|l|l|c|c|c|c|c|c|}
\hline$№$ п/п & Сорт & $\mathrm{Xi}$, кг/M & bi & OACi & CACi & Sgi, \% & СЦГі \\
\hline 1 & Солнышко - стандарт & $1,9 \pm 0,5$ & $-2,12$ & 0,2 & 0,04 & 2,1 & 1,78 \\
\hline 2 & F24 & $1,5 \pm 0,2$ & $-1,01$ & $-0,2$ & 0,15 & 9,8 & 0,96 \\
\hline 3 & F27 & $2,3 \pm 0,1$ & $-1,88$ & 0,5 & 0,10 & 4,3 & 1,92 \\
\hline 4 & F29/1 & $1,5 \pm 0,4$ & $-0,35$ & $-0,3$ & 0,30 & 20,2 & 0,36 \\
\hline 5 & F29/2 & $1,9 \pm 0,6$ & $-0,06$ & 0,1 & 0,34 & 18,4 & 0,56 \\
\hline 6 & F29/3 & $1,9 \pm 0,2$ & $-1,20$ & 0,1 & 0,15 & 8,1 & 1,29 \\
\hline 7 & F29/4 & $1,5 \pm 0,3$ & $-0,43$ & $-0,3$ & 0,21 & 14,4 & 0,67 \\
\hline 8 & F30 & $1,5 \pm 0,6$ & 0,33 & $-0,3$ & 0,34 & 23,4 & 0,16 \\
\hline 9 & F171/1 & $2,1 \pm 0,6$ & $-0,27$ & 0,3 & 0,41 & 19,6 & 0,53 \\
\hline 10 & F171/2 & $1,7 \pm 0,4$ & $-0,62$ & $-0,1$ & 0,19 & 11,4 & 0,94 \\
\hline
\end{tabular}

Примечание: $\mathrm{Xi}$ - среднее значение признака, кг/м2; bi - коэффициент регрессии; $\mathrm{CACi} \mathrm{-} \mathrm{специфическая} \mathrm{адаптивная} \mathrm{способность;} \mathrm{Sgi} \mathrm{-} \mathrm{относительная} \mathrm{стабильность}$ генотипа; СЦГі - селекционная ценность генотипа.

Относительная стабильность генотипа (Sgi) выступает важным параметром при селекции культур на адаптивность. Она является составляющей характеристики селекционно ценных генотипов, сочетающих высокую потенциальную продуктивность и экологическую устойчивость. При значении Sqi $<10 \%$ уровень экологической изменчивости признака незначительный, от 10 до $20 \%$ - средний и выше $20 \%$ - значительный. Высоким уровнем экологической изменчивости обладали линии F30 (23,4 \%) и F29/1 (20,2 \%).

Лучшим для зоны будет являться образец, в генотипе которого сочетаются высокие показатели параметров изучаемого признака, а также ОАСi и СЦГі. Наибольшими показателями по изучаемым параметрам обладала линия F27. Среди изученных линий по показателю СЦГі выделились формы F27 $(1,92)$, F29/3 $(1,29)$ и F24 $(0,96)$.

Оценка стабильности форм, проведенная на основе сумм отклонений урожайности изучаемых линий, показала, что чем ниже максимальная урожайность, тем выше стабильность генотипа (рисунок). 


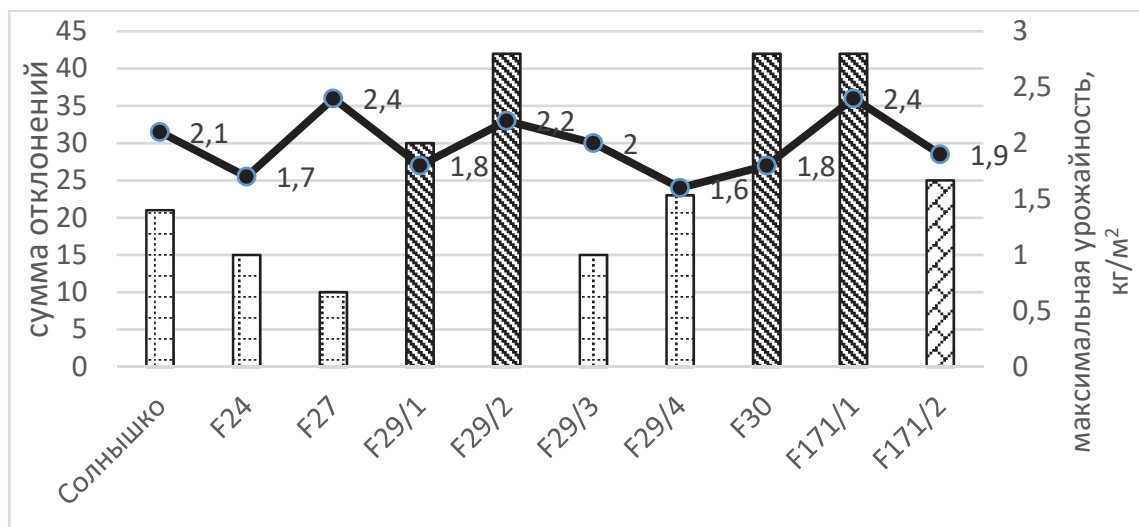

Рисунок. Оценка стабильности генотипов по урожайности и суммам отклонений (2017-2019 гг.).

Для производства интерес представляют генотипы, сочетающие высокий уровень продуктивности и стабильности. Наиболее оптимальными значениями по параметрам обладают перспективные линии F27, F29/3, F24.

Многолетняя оценка 9 перспективных линий фасоли овощной показала, что, в основном образцы существенно отличаются между собой по степени реакции на изменение условий выращивания.

Среди перспективных форм, выделены 3 генотипа (F27, F29/3, F24), сочетающие высокую продуктивность со средовой устойчивостью, которые гарантированно обеспечивают стабильную урожайность и высокое качество продукции.

\section{Список литературь}

1. Кильчевский А.В. Генетико-экологические основы селекции растений / А.В. Кильчевский / Вестник ВОГиС. - Беларусь, 2005. - №4 (9). - С. 518-526.

2. Методические указания. Коллекция мировых генетических ресурсов зерновых бобовых ВИР: пополнение, сохранение и изучение (под ред. Вишняковой М.А.). СПб.: ООП «Копи-Р. Групп», $-2010-142$ с.

3. Методические указаниям по изучению образцов мировой коллекции фасоли СПб, 1987. - 60 с.

4. Якубенко О.Е. Перспективные генотипы фасоли овощной / О.Е. Якубенко, О.В. Паркина // Актуальные проблемы агропромышленного комплекса: Сборник трудов научно-практической конференции преподавателей, аспирантов, магистрантов и студентов Новосибирского государственного аграрного университета. - ИЦ «Золотой колос». - 2018. - С. 56-59. 